\title{
CARACTERIZAÇÃo FÍSICO-QUÍMICA DE ALGUMAS TUBEROSAS AMILÁCEAS ${ }^{1}$
}

\author{
Magali LEONEL ${ }^{2, *}$, Marney Pascoli CEREDA ${ }^{3}$
}

\section{RESUMO}

As principais fontes de amido comercial no mundo são o milho, a batata e a mandioca. Entretanto, nos últimos anos vem crescendo o interesse em amidos naturais que possam ser utilizados pela indústria alimentícia. Assim, este trabalho teve por objetivo caracterizar, quanto à composição físico-química, açafrão, ahipa, araruta, batata-doce, biri, inhame e mandioquinha-salsa, tuberosas amiláceas potencialmente passiveis de introdução como matérias-primas de interesse comercial. Amostras das tuberosas foram analisadas quanto ao teor de umidade, cinzas, proteina, matéria graxa, açúcares redutores e totais, fibras e amido. Os resultados obtidos mostraram que das tuberosas analisadas as que apresentaram maior teor de amido foram a araruta (Maranta arundinacea), o inhame (Dioscorea sp) e o biri (Canna edulis), sendo que o inhame e o biri apresentaram também o maior rendimento potencial em toneladas de amido/hectare. Palavras-chave: rizomas; raizes; amido; composição.

\section{SUMMARY}

PHYSICOCHEMICAL CHARACTERIZATION OF SOME STARCHY TUBERS. The commercial starches of the world come mainly from corn, potato and cassava. However, food industries are searching for native starches that can satisfy the technical and economic demands for food production. The present study was conducted to evaluate the physicochemical composition of starchy tubers, saffron, ahipa, arrowroot, sweet potato, biri, yam and arracacha attempting to characterize their industrial potential. The contents of moisture, ash, protein, lipids, reducing and total sugars, fibers and starch were determined in some starchy tubers. The results showed high starch content in arrowroot (Maranta arundinacea), yam (Dioscorea sp) and biri (Canna edulis). The best results for potential starchy yield (t starch/ha) were to yam and biri.

Keywords: rhizomes; roots; starch; composition.

\section{1 - INTRODUÇÃO}

O amido é a principal substância de reserva nas plantas superiores, fornecendo de 70 a $80 \%$ das calorias consumidas pelo homem. Os depósitos permanentes do amido nas plantas ocorrem nos orgãos de reserva como é o caso de grãos em cereais (milho, arroz) e de tubérculos e raízes (batata e mandioca).

As indústrias alimentícias são as maiores consumidoras de amido, entretanto, este polímero é usado também em um grande número de processos industriais destacando-se seu uso pelas indústrias química e têxtil. Atualmente, devido às restrições a amidos modificados impostas principalmente pelas indústrias alimentícias, as empresas produtoras de amido no mundo vêm mostrando um interesse cada vez maior em amidos naturais com características que atendam o mercado consumidor $[2,5,6,16]$. Frente a este fato as pesquisas em torno de novas matérias-primas amiláceas têm se intensificado nos últimos anos. Neste ponto, os países em regiões tropicais, como o Brasil, apresentam grande vantagem em relação aos principais produtores de amido no mundo, que estão localizados em regiões temperadas, devido à variedade de culturas tropicais amiláceas.

Dentre as amiláceas tropicais merecem destaque, além da mandioca cujo Brasil é o segundo país produtor, a araruta (Maranta arundinacea), a mandioquinhasalsa (Arracacia xanthorrhiza) e a batata-doce (Ipomoea batatas), visto o interesse do mercado consumidor, prin- cipalmente para uso desses amidos em panificação e "baby foods" [6, 13, 14, 21, 29].

Originária dos Andes, a mandioquinha-salsa é cultivada no Brasil na região Centro-Sul, principalmente em áreas de elevada altitude e clima ameno de Minas Gerais, Paraná, Santa Catarina, Espírito Santo e São Paulo, onde ocorrem condições climáticas similares às de seu local de origem [7, 24]. A mandioquinha-salsa ou batata-baroa é uma raiz de uso culinário no Brasil, sendo que em 1998 o Estado de São Paulo cultivou 972 hectares, com produção de 11.000 toneladas [8]. A colheita é realizada, normalmente, aos 11-12 meses de ciclo. A mandioquinha é recomendada em dietas para crianças e idosos devido ao seu conteúdo de cálcio e fósforo $(65,25$ e $55,00 \mathrm{mg} / 100 \mathrm{~g}$ material fresco). Outro fator determinante de seu uso em dietas especiais são as características do seu amido, que contém amilose em torno de $23 \%$, grânulos arredondados variando de 5 a $27 \mu \mathrm{m}$, difícil retrogradação e sinerese, fatores que concorrem para sua grande digestibilidade [13, 21].

A batata-doce (Ipomoea batatas), planta originária da América tropical, é uma das tuberosas mais populares do Brasil, sendo consumida na forma assada ou cozida e industrializada na forma de doces. A área cultivada de batata-doce no mundo é de 8.867 (1000ha) sendo a terceira tuberosa mais cultivada. No Brasil a área cultivada foi de 18.000 hectares em 1998, com produção de 270.000 toneladas, sendo que o Estado de São Paulo foi responsável por $12 \%$ da produção [8].

\footnotetext{
${ }^{1}$ Recebido para publicação em 15/05/01. Aceito para publicação em 12/11/01.

${ }_{2}^{2}$ Pesquisadora Doutora-Centro de Raizes e Amidos Tropicais/UNESP - Fazenda Experimental Lageado s/n, Botucatu-SP. E-mail: pesq1cerat@fca.unesp.br

${ }^{3}$ Professora Titular CERAT/UNESP - Botucatu-SP. E-mail: cereda@terra.com.br

* A quem a correspondência deve ser enviada.
} 
No processamento de raizes de batata-doce em uma fecularia brasileira de mandioca foi observada menor eficiência da planta no processamento da batata-doce (18,3\% de rendimento), quando comparado com o de mandioca $(25,5 \%$ de rendimento), indicando a necessidade de ajustes dos equipamentos para uma melhor extração do amido de batata-doce [14].

A araruta é uma planta proveniente da América Latina e se encontra de forma nativa nas matas venezuelanas. O tamanho dos rizomas oscila entre 10 e $25 \mathrm{~cm}$, são de forma fusiforme, alongados e apresentam pequenos segmentos, separados entre si por leves estrangulamentos providos de escamas. Três são os cultivares de importância no Brasil, a creoula, a banana e a comum, que é a mais difundida. A variedade comum é a que produz fécula de melhor qualidade; seus rizomas são claros, em forma de fuso, cobertos por escamas e atingem até 30 centímetros dependendo da qualidade do solo, embora o tamanho normal varie de 10 a 25 centímetros. A creoula produz rizomas na superficie da terra, em touceiras, que precisam ser lavados várias vezes para perder a camada escura, caso contrário, produzem uma fécula negra e de baixa qualidade.[9, 16].

O açafrão (Curcuma longa) é um rizoma originário do Sudeste da Ásia e sua utilização como planta condimentar ou especiaria tem sido relatada como iniciada há milênios. $\mathrm{O}$ amido não tem sido muito utilizado pela indústria, porque sua extração é considerada como uma atividade secundária. Os produtos principais são a curcumina e o óleo essencial os quais são usados como condimento, corante natural, e em aplicações farmacológicas. Os rizomas são secos e moídos e do pó se extrai 2,5-5\% de óleo essencial, 2-8\% de curcumina e 25 a $70 \%$ de amido [10]. Portanto, devido ao elevado teor de amido e ao fato do processo de extração não interferir na obtenção dos produtos comerciais, torna-se promissor este rizoma como uma matéria-prima para a indústria de amido.

O inhame (Dioscorea sp) é também uma amilácea bastante cultivada para o consumo direto, sendo produzido a mais de 2000 anos em regiões de clima tropical e subtropical. No mundo a área cultivada é de 1.080 (1000 ha), entretanto, no Brasil o inhame é uma cultura de pequenos produtores, utilizada no consumo direto. Algumas indústrias utilizam os rizóforos no preparo de papinhas para bebê. Contudo não existe processamento do inhame para a obtenção de amido [1]. Estimase que no mundo, em 1998, foram cultivados 3320 (1000ha) com inhame [8, 17].

Outras duas amiláceas tropicais de origem andina são o biri (Canna edulis) e o ahipa (Pachyrhizus ahipa), os quais têm o amido extraído de forma artesanal nas regiões dos Andes.

O biri é uma planta perene que alcança de 1 a 2 metros de altura, com folhas ovais oblongas e inflorescências vermelhas, sendo cultivada no Brasil apenas como planta ornamental. O ciclo da cultura é de 10 a 12 meses e o rendimento chega a 30t/ha. A colheita é feita após 6 a 8 meses em terrenos férteis [13, 21]. O consumo direto das raízes é quase impossivel devido a existência de fibras grossas, sendo o biri mais conhecido nos paises andinos por suas folhas, que servem de embalagens para muitas preparações alimentícias [11]. O seu amido é de fácil extração, pois os grânulos são grandes (35 a $101 \mu \mathrm{m})$. Trata-se geralmente de um produto elaborado em fundo de quintal, em processo de transformação artesanal. Porém, há alguns exemplos em regiões da Colômbia, onde empresas conseguem obter ate $300 \mathrm{~kg} /$ dia de amido. O rendimento da extração é muito baixo e não ultrapassa os $13 \%$, o que se deve ao processamento artesanal e antiquado [23].

Já o ahipa é uma leguminosa originária da América do Sul e pode ser considerada uma matéria-prima amilácea muito interessante visto ao rápido desenvolvimento (colheita em 5 meses), considerável adaptabilidade à variações climáticas e elevado teor de amido (45-55\% base seca), o qual apresenta 95 a 99\% de amilopectina. O $P$. ahipa apresenta um rendimento agrícola de 30-50t/ha, sendo utilizado as sementes para o plantio [27].

Para a viabilização da introdução de uma nova matéria-prima nas indústrias produtoras de amido é preciso considerar a parte agrícola da cultura, a composição físico-química da porção a ser processada e os resíduos gerados. Sob o ponto de vista tecnológico, a presença de outros componentes que não amido na matéria-prima deve ser considerada. Estes compostos podem interferir no processo de extração do amido, alterando o rendimento final, como é o caso das fibras (teor e tipo), proteínas, gorduras e gomas [25].

Neste trabalho objetivou-se avaliar a composição fisico-química das tuberosas amiláceas: açafrão, ahipa, araruta, batata-doce, biri, inhame e mandioquinha-salsa, visando estabelecer potencialidades destas como matérias-primas para as indústrias produtoras de amido do Brasil.

\section{2 - MATERIAIS E MÉTODOS}

As tuberosas amiláceas foram cultivadas no Campo Experimental do Centro de Raízes e Amidos Tropicais / UNESP. O clima da região caracteriza-se por temperado sem inverno seco, com precipitação anual de $1314 \mathrm{~mm}$, a terra é roxa, estrutura álica, textura argilosa, latossólica. Latitude $22^{\circ} 52^{\prime} 47^{\prime \prime} \mathrm{S}$, longitude $48^{\circ} 25^{\prime} 12^{\prime \prime} \mathrm{W}$ e altitude de $810 \mathrm{~m}$. A Tabela 1 mostra a época de plantio e colheita das tuberosas avaliadas.

TABELA 1. Meses de plantio e colheita das tuberosas amiláceas.

\begin{tabular}{lcc}
\hline Tuberosas & Plantio em 1999 & Colheita em 2000 \\
\hline Açafrão & Novembro & Julho \\
Ahipa & Outubro & Julho \\
Araruta & Setembro & Agosto \\
Batata-doce & Outubro & Maio \\
Biri & Outubro & Julho \\
Inhame & Agosto & Agosto \\
Mandioquinha-salsa & Abril & Abril \\
\hline
\end{tabular}

As tuberosas (1kg) colhidas foram lavadas, secas e amostradas para a determinação da umidade inicial, 
pH e acidez titulável [4]. O restante do material foi fatiado e colocado em estufa de circulação de ar a $50^{\circ} \mathrm{C}$ para a desidratação e conservação das amostras.

As amostras desidratadas foram avaliadas quanto aos teores de: umidade, cinzas, proteína, matéria graxa, fibras, açúcares redutores e totais e amido [4, 22]. Foram feitas três repetições de cada amostra por análise.

O teor de umidade das amostras foi determinado usando-se estufa com circulação de ar a $105^{\circ} \mathrm{C}$ por 8 horas [4].

Para a determinação do teor de cinzas utilizou-se mufla a $550^{\circ} \mathrm{C}$ por 2 horas [4].

A análise do teor de fibra bruta foi feita através de digestão do material em solução de $\mathrm{H}_{2} \mathrm{SO}_{4}$ a $1,25 \% \mathrm{p} / \mathrm{v}$ por 30 minutos, seguida de $\mathrm{NaOH} 1,25 \% \mathrm{p} / \mathrm{v}$ por mais 30 minutos [4].

A determinação do teor de matéria graxa foi realizada em extrator Soxleth completo, utilizando-se éter de petróleo para a extração [4].

Para a avaliação do teor de proteína das amostras utilizou-se destilador micro-Kjeldahl e bloco digestor, avaliando-se a porcentagem de nitrogênio na amostra. A conversão para proteína foi feita por $\mathrm{N}$ x 6,25 [4].

Na determinação dos açúcares totais pesou-se $0,5 \mathrm{~g}$ de amostra em um erlenmeyer de $250 \mathrm{~mL}$ acrescentando-se $30 \mathrm{~mL}$ de etanol absoluto P.A., em seguida adicionou-se $30 \mathrm{~mL}$ de água destilada, levando-se a banho com aquecimento entre $60-65^{\circ} \mathrm{C}$ por 60 minutos. Depois se acrescentou $1 \mathrm{~mL}$ de $\mathrm{HCl}$ P.A. concentrado e agitou-se, retornando ao banho por mais uma hora na mesma temperatura. Após este tempo resfriou-se a amostra e esta foi transferida para balão volumétrico de $250 \mathrm{~mL}$ efetuando-se a neutralização com solução saturada de carbonato de sódio. Adicionaram 1 a $2 \mathrm{~mL}$ de solução de hidróxido de bário a $0,3 \mathrm{~N}$ e 1 a $2 \mathrm{~mL}$ de solução de sulfato de zinco a $5 \%$, completou-se o volume do balão com água destilada. Após agitação retirou-se uma amostra do material e centrifugou-se, sendo então determinado o teor de açúcares totais [26].

$\mathrm{Na}$ análise do teor de açúcares redutores 1 grama de amostra foi colocado em um erlenmeyer de $250 \mathrm{~mL}$ sendo adicionado $50 \mathrm{~mL}$ de água destilada. Os frascos permaneceram em banho com aquecimento a $65^{\circ} \mathrm{C}$ por 30 minutos, sendo em seguida retirados e resfriados. $\mathrm{O}$ material foi transferido para balão volumétrico de $100 \mathrm{~mL}$ passando por papel de filtro comum, sendo o volume completado com água destilada. Retirou-se uma amostra e efetuou-se a determinação do teor de açúcares redutores [26].

Para a determinação do teor de amido nas amostras utilizou-se o método enzimático de hidrólise. Pesou-se $200 \mathrm{mg}$ de amostra finamente peneirada $(0,25 \mathrm{~mm})$ e acrescentou-se $42 \mathrm{~mL}$ de água. Para a hidrólise inicial utilizou-se $2 \mathrm{~mL}$ de Termamyl 120L $(\alpha-$ amilase), inclusive na prova em branco, e levou-se em banho-maria com agitação na temperatura de $90^{\circ} \mathrm{C}$ por
15 minutos. Decorrido este período esperou-se abaixar a temperatura para $60^{\circ} \mathrm{C}$ e adicionaram-se $2,5 \mathrm{~mL}$ de tampão acetado $4 \mathrm{M}, \mathrm{pH} 4,8$ e em seguida $2 \mathrm{~mL}$ de solução de amiloglucosidase na concentração de $1,5 \mathrm{mg} / \mathrm{mL}$. $\mathrm{O}$ material permaneceu a $60^{\circ} \mathrm{C}$ no banho com agitação por 2 horas. Após o material ser resfriado determinouse o teor de açúcar, sendo feita a conversão à amido pela multiplicação da porcentagem de açúcar obtida pelo fator 0,9 [22, 26].

A partir dos resultados obtidos na caracterização das tuberosas e de dados da literatura sobre produtividade agrícola de cada cultura estimou-se a produtividade em toneladas de amido/hectare para cada tuberosa amilácea. O cálculo da produtividade foi realizado através da multiplicação da quantidade de amido por tonelada de matéria-prima fresca pela produtividade agrícola da cultura.

\section{3 - RESULTADOS E DISCUSSÃO}

Os resultados obtidos na caracterização das tuberosas amiláceas (Tabela 2) mostraram baixo teor de matéria seca nas raizes de Pachyrhizus ahipa (18\%) e nos rizomas de açafrão (Curcuma longa) (18,8\%). No caso do açafrão, como o amido poderia ser obtido do resíduo da extração das curcuminas, o baixo teor de matéria seca não seria problema. Já para o ahipa, em caso de processamento industrial, o elevado teor de água vegetal e baixo teor de matéria seca seriam importantes na definição do processo, que deverá levar em consideração possiveis formas de aproveitamento dos outros componentes da raiz de ahipa.

As amiláceas com maior teor de matéria seca foram a araruta, batata-doce, biri e o inhame, contudo a batata-doce apresentou um elevado teor de açúcares totais e redutores $(6,99$ e $5,74 \%)$, o que a torna uma matériaprima utilizável não somente para a extração do amido, mas para a produção de hidrolisados e fermentados. Elevado teor de açúcares também foi observado nas raízes de ahipa $(4,24$ e $2,68 \%)$, sendo que este dado confirma o observado por SORENSEN, GRÜNEBERG, AERTING [27] em 19 variedades de P. ahipa. Como esta raiz não tem cultivo comercial no Brasil, mas apresenta composição que possibilita o seu processamento para a produção de amido e também de hidrolisado, estudos que visem a avaliação da cultura como matéria-prima para estas indústrias são necessários.

A mandioquinha-salsa apresentou composição centesimal com valores próximos aos encontrados na literatura em análises dessa raiz: umidade $64,12-81,37 \%$, amido $16,91-25,49 \%$, açúcares totais $0,65-1,98$, fibras $0,60-1,24$, cinzas 1,05 - 1,38, proteína 0,60 1,85 , lipídios $0,19-0,35$ [20]. A mandioquinha é uma cultura já bem estabelecida no Brasil, contudo, como é comercializada para o consumo direto, não existem trabalhos na seleção de variedades, condições de plantio e época de colheita, que visem um melhor rendimento em amido. Entretanto, o processamento dessa matéria-prima para a obtenção de amido deve ser considerado, visto o mercado de alimentos infantis $[12,18]$. 
Quanto à composição centesimal do inhame os resultados obtidos foram semelhantes aos encontrados por BERMUDEZ [6] que foram: 28,1 - 29,5\% de matéria seca com 70,3 - 79,5\% de amido, 1,7 - 4,3\% de açúcares totais, $0,1-0,7 \%$ de açúcares redutores, 0,6 - 2,9\% de fibra, 4,6 - 7,1 de proteína.

Uma dificuldade na obtenção do amido do inhame é a presença de mucilagens que mantêm o amido em suspensão não permitindo a sedimentação. Alguns trabalhos sugerem o uso de amônia para a melhoria da extração e qualidade do produto, contudo, modificações nas propriedades nativas do amido podem ocorrer [21].

Quanto às fibras foi observado os maiores valores nos rizomas de araruta e açafrão, sendo este fator também muito importante no processo de extração de amido. O processamento de matérias-primas com maior teor de fibras requer ajustes na moagem e extração, etapas em que ocorrem o rompimento das células para a liberação dos grânulos e a lavagem do material. Contudo, o bagaço gerado poderia ser aproveitado como fonte de fibras dietéticas, o que poderia contribuir grandemente para a viabilização do processamento, pois geraria uma outra receita para a indústria [15].

A partir dos resultados obtidos em teor de amido e dos dados de literatura da produtividade agrícola de cada tuberosa amilácea estabeleceu-se a produtividade potencial de amido por hectare. Os resultados obtidos (Tabela 3, Figura 1) mostraram bons rendimentos em amido para as culturas do biri e inhame $(5,5$ e 6,1 t amido/ha, respectivamente) e um baixo rendimento para o açafrão (0,97t amido/ha), quando comparados ao rendimento citado na literatura para mandioca $(7,5 \mathrm{t}$ amido/ha) [28]. $\mathrm{O}$ inhame já tem uma tradição de cultivo em alguns Estados do país, mas para o biri os dados de produtividade são referentes a cultivos nos países andinos.

O inhame vem sendo cultivado no Brasil para o consumo direto, onde somente os rizóforos são aproveitados. Contudo, para o processamento industrial toda porção tuberosa pode ser usada, o que aumentaria o rendimento em amido.
Estas informações são importantes na tomada de decisão pelas indústrias produtoras de amido, pois se existir mercado para um determinado tipo de amido, será preciso realizar trabalhos de melhoria de rendimento da cultura, visto que nenhuma dessas culturas têm sido plantadas com o objetivo de produção de amido comercial.

TABELA 3. Rendimento potencial de amido das tuberosas amiláceas por hectare.

\begin{tabular}{lccc}
\hline Tuberosas & \%amido (base úmida) & $\begin{array}{c}\text { Produtividade } \\
\text { Agrícola (t/ha) } *\end{array}$ & $\begin{array}{c}\text { Rendimento potencial } \\
\text { de amido (t/ha) }\end{array}$ \\
\hline Açafrão $^{1}$ & 8,83 & 11 & 0,97 \\
Ahipa $^{2}$ & 7,68 & 40 & 3,1 \\
Araruta $^{3}$ & 24,23 & 15 & 3,6 \\
Batata-doce $^{4}$ & 14,72 & 20 & 2,9 \\
Biri $^{5}$ & 18,45 & 30 & 5,5 \\
Inhame $^{6}$ & 20,43 & 30 & 6,1 \\
Mandioquinha-salsa $^{7}$ & 15,17 & 22 & 3,3 \\
\hline
\end{tabular}

* dados de literatura
1 GOTO [10]; 2 SORENSEN, GRÜENBERG, AERTING [27]; ${ }^{3}$ DA SILVA \& MONTEIRO [9]; ${ }^{4}$ AGRIDATA [3]; ${ }^{5}$ HERMANN [11]; ${ }^{6}$ ABRAMO [1]; ${ }^{7}$ MONTEIRO et al. [19]

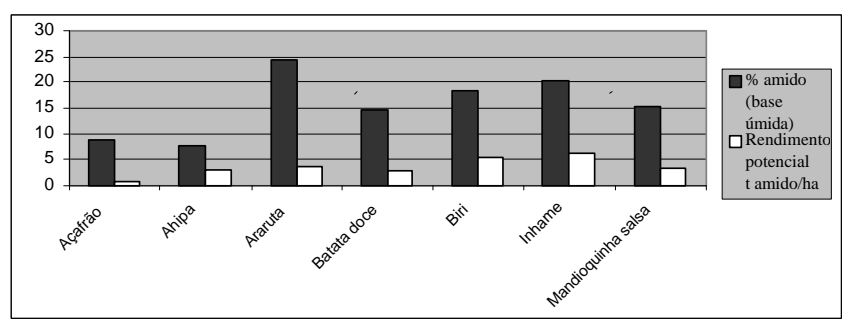

FIGURA 1. Relação porcentagem de amido e rendimento potencial de amido por hectare.

\section{4 - CONCLUSÕES}

A partir dos resultados obtidos foi possivel concluir que a araruta, o biri e o inhame apresentam-se como amiláceas com potencial de uso como matéria-prima industrial. Entretanto, o estudo das propriedades dos amidos poderá justificar a produção e o processamento de uma cultura com baixo rendimento em amido.

TABELA 2. Caracterização físico-química das tuberosas amiláceas (\% base úmida) a

\begin{tabular}{|c|c|c|c|c|c|c|c|c|c|c|}
\hline $\begin{array}{l}\text { Variáveis } \\
\text { Tuberosas }\end{array}$ & Umidade & Amido & $\begin{array}{c}\text { Açúcares } \\
\text { solúveis } \\
\text { totais }\end{array}$ & $\begin{array}{l}\text { Açúcares } \\
\text { redutores }\end{array}$ & Fibras & Proteína & Cinzas & $\begin{array}{c}\text { Matéria } \\
\text { graxa }\end{array}$ & pH & $\begin{array}{l}\text { Acidez } \\
\text { titulável }\end{array}$ \\
\hline Açafrão & $81,23 \pm 0,47$ & $8,83 \pm 0,27$ & $2,02 \pm 0,02$ & $0,83 \pm 0,03$ & $1,78 \pm 0,08$ & $2,02 \pm 0,04$ & $2,01 \pm 0,03$ & $0,91 \pm 0,02$ & $6,54 \pm 0,04$ & $10,95 \pm 0,17$ \\
\hline Ahipa & $82,00 \pm 0,66$ & $7,68 \pm 0,46$ & $4,24 \pm 0,21$ & $2,68 \pm 0,07$ & $0,74 \pm 0,05$ & $1,00 \pm 0,04$ & $0,40 \pm 0,03$ & $0,10 \pm 0,01$ & $5,52 \pm 0,05$ & $12,04 \pm 0,69$ \\
\hline Araruta & $68,20 \pm 0,68$ & $24,23 \pm 0,38$ & $1,08 \pm 0,06$ & $0,85 \pm 0,04$ & $1,44 \pm 0,12$ & $1,34 \pm 0,02$ & $1,83 \pm 0,02$ & $0,19 \pm 0,01$ & $6,67 \pm 0,03$ & $9,19 \pm, 028$ \\
\hline Batata-doce & $67,73 \pm 1,07$ & $14,72 \pm 0,18$ & $6,99 \pm 0,13$ & $5,74 \pm 0,12$ & $1,39 \pm 0,05$ & $1,33 \pm 0,01$ & $1,32 \pm 0,01$ & $0,35 \pm 0,01$ & $6,29 \pm 0,01$ & $7,93 \pm 0,08$ \\
\hline Biri & $75,67 \pm 0,98$ & $18,45 \pm 0,77$ & $0,83 \pm 0,05$ & $0,49 \pm 0,01$ & $1,00 \pm 0,03$ & $1,09 \pm 0,06$ & $1,67 \pm 0,07$ & $0,33 \pm 0,04$ & $6,81 \pm 0,03$ & $3,87 \pm 0,15$ \\
\hline Inhame & $75,30 \pm 0,97$ & $20,43 \pm 0,13$ & $1,19 \pm 0,05$ & $0,61 \pm 0,04$ & $0,77 \pm 0,04$ & $0,13 \pm 0,02$ & $1,12 \pm 0,06$ & $0,12 \pm 0,01$ & $6,13 \pm 0,07$ & $6,66 \pm 0,08$ \\
\hline
\end{tabular}

a: os resultados são médias de três determinações. 


\section{5 - REFERÊNCIAS BIBLIOGRÁFICAS}

[1] ABRAMO, M.A. Taioba. In: ABRAMO, M.A. Taioba, cará, inhame: o grande potencial inexplorado. Ícone Editora, Série II, Campinas, 1990. p.57-63.

[2] AGBOR-EGBE, T., RICKARD, J.E. Evaluation of the chemical composition of fresh and stored edible aroids. J. Sci. Food Agric., v.53, p. 487-495, 1990.

[3] AGRIDATA (2000). http:// www.agridata.mg.gov.br

[4] ASSOCIATION OF OFFICIAL ANALYTICAL CHEMISTS. Official methods of analysis. 13. ed. Washington, 1980. 109p.

[5] BEMILLER, J.N. Starch modification: changes and prospects. Starch/Stärke, v.49, n.4, p.127-131, 1997.

[6] BERMUDEZ, J.J.H. Valorización de las amilácea "no cereales"cultivadas en los pasíses andinos: estudio de las propriedades fisicoquimicas y funcionales de sus almidones y de la resistência a diferentes tratamientos estressantes. 1997, 150p. Trabajo de Grado, Faculdad de Ingenieria de Alimentos, Universidad de Bogotá, Colômbia.

[7] CÂMARA, F.L.A. Mandioquinha-salsa: grande potencial com novas técnicas. Agropecuária Catarinense, v. 6, n.2, p.25-27, 1993.

[8] CAMARGO FILHO, W.P., MAZZEI, A.R., ALVES, H.S. Mercado de raízes e tubérculos: análise de preços. Informações econômicas, v.31, n.2, p.36-44, 2001.

[9] DA SILVA J.R MONTEIRO D.A. Cultura da araruta industrial: Instituto Agronômico de Campinas, seção de raízes e tuberculos, Divisão de plantas industriais, Boletim n. 190, Julho 1969, $11 \mathrm{p}$.

[10]GOTO, R. Épocas de plantio, adubações fosfatadas e unidades térmicas em cultura de açafrão (Curcuma longa L.). Jaboticabal, 1993, 93p. Tese de Doutorado (Doutorado em Agronomia) - Faculdade de Ciências Agrárias e Veterinárias, Universidade Estadual Paulista (UNESP), 93p.

[11] HERMANN,M. Arracacha and achira processing and product development. CIP Centro International de la Papa, Progress report 6310, Quito Ecuador, Mimeograph 8p. 1994.

[12] HERMANN, M. Arracacha. Arracacha xanthorrizza Bancroft. In: HERMANN, M., HELLER, J. (Ed.) Andean roots and tubers: Ahipa, arracacha, maca and yacon. Promoting the conservation and use of the underutilized and neglected crops. Internation Plant Genetic Resource Institute, Germany, 1997. Cap 3, p.75-172.

[13] KIBUUKA, G. K.; MAZZARI, M.R. Isolamento, caracterização físico-química e perspectivas industriais de amido de batata baroa (Arracacia xanthorhyza Bancroft Syn). In: XXI Congresso Brasileiro de Olericultura, Campinas, SP, 1981, p.34.

[14] LEONEL, M., CEREDA, M.P, JAQUEY, S. Processamento industrial de fécula de mandioca e batata-doce - um estudo de caso. Ciência e Tecnologia de Alimentos, v.18, n.3, p.343-345, 1998.

[15] - LEONEL, M., CEREDA, M. P, ROAU, X.. Cassava bagasse as dietary product. Tropical Science, v.38, p. 224-228, 1998.
[16] MESSENGER, B. Going native. Food processing, january, p. 58-59, 1997.

[17] MONTALDO.A. Cultivo de raices y tuberculos tropicales, Instituto Interamericano de Ciencias Agricolas de la OEA, Lima, Peru, 1972 p257.

[18] MONTEIRO, D.A., TREMOCOLDI, W.A., LORENZI, J.O., PERESSIN, V.A. A realidade da mandioquinha-salsa no Estado de São Paulo. O Agronômico, v.45, n.2/3, p.2025, 1993.

[19] MOORTHY, S.N. Tuber crop starches. Kerala: Central Tuber Crops Research Institute, 1996. v.1.

[20] PEREIRA, A. S. Valor nutritivo da mandioquinha-salsa. Informe agropecuáro, v.19, n.190, p.11-12, 1997.

[21] PÉREZ, E., LARES, M., GONZÁLEZ, Z. Some characteristics of sagu (Canna edulis) and zulu (Maranta sp) rhizomes. J. Agric. Food Chem., v.45, p. 2546-2549, 1997.

[22] RICKARD, J. E., BEHN, K. R. Evaluation of acid and enzyme hydrolitic methods for determination of cassava starch. J. Sci. Food Agric., v.41, n. 4, p. 373 - 9, 1987.

[23] SANTACRUZ, S.; SWENSSON, E.; KocH, K.; ELIASSON, A. C., RUALES, J. physicochemical characterizations of three unconventional sources of starch from the Andean region in Ecuador. Trop. Agriv., v.75, n.2, p.302-304, 1998.

[24] SANTOS, F.F. Características sócio-econômicas no processo de produção de mandioquinha-salsa no Brasil. Horticultura brasileira, v.11, n.1, p.95, 1993.

[25] SARMENTO, S.B.S. Caracterização da fécula de mandioca (Manihot esculenta C.) no periodo de colheita de cultivares de uso industrial. São Paulo, 1997. 162p. Tese de doutorado (Doutor em Ciências) - Faculdade de Ciências Farmacêuticas, Universidade de São Paulo (USP).

[26] SOMOGY, M. Determination of blood sugar. J. Biol. Chem., n.160, p. $69-73,1945$.

[27] SOREnsen, M., GRÜNEBERG, W., ÆERTING, B. Ahipa. Pachyrhizus ahipa (Wedd.) Parodi. In: HERMANN, M., HELLER, J. (Ed.) Andean roots and tubers: Ahipa, arracacha, maca and yacon. Promoting the conservation and use of the underutilized and neglected crops. Internation Plant genetic Resource institute, Germany, 1997. Cap 2, p.75-172.

[28] VILPOUX, O., CEREDA, M. P. Caracterização das fecularias no Brasil. Botucatu: Centro de Raizes Tropicais, UNESP, 1995. 58p.

[29] ZANIN, A.C.W. Características de raizes, propágulos e cepas de três clones de mandioquinha-salsa. Científica, v.13, n.1/2, p. 1-6, 1985.

\section{6- AGRADECIMENTOS}

Agradecemos à Fundação de Amparo à Pesquisa do Estado de São Paulo (FAPESP) pelo auxílio financeiro e a Novo Nordisk pela concessão das enzimas utilizadas na determinação do teor de amido. 